Artigo Original

\title{
Perspectivas dos gestores ambientais dos municípios consorciados ao CIGRES no processo de implantação da coleta seletiva
}

\author{
Perspectives of environmental managers of CIGRES-consultant municipalities in the selective \\ collection process
}

\author{
Deisy Brasil Gonçalves' e Damaris Kirsch Pinheiro"
}

\section{Resumo}

Ainda são insuficientes os municípios brasileiros que realizam ações em prol de um gerenciamento adequado dos resíduos sólidos urbanos. Diversos fatores contribuem para que o trabalho de educação ambiental em muitos casos sejam ausentes ou pouco eficazes. Este estudo teve como objetivo identificar os métodos de educação ambiental, as fragilidades e potencialidades no processo de implantação do sistema, visando análise, discussão e proposição de ferramentas, soluções e/ou mitigação das dificuldades encontradas. Para isso, foi realizada uma pesquisa qualiquantitativa direcionada aos gestores ambientais dos municípios da região noroeste do estado do Rio Grande do Sul-RS. Diante dos resultados constatou-se que muitos municípios ainda estão atrasados neste processo e a grande maioria tem se deparado com inúmeros desafios, entre eles a falta de apoio dentro da própria administração municipal e da população em geral. Evidenciou-se também a necessidade da implantação deste sistema ser intensa e ininterrupta, integrando atividades de informação, sensibilização e mobilização de todos os envolvidos. Posterior a análise dos dados, realizou-se uma palestra com os gestores ambientais onde foi apresentado e discutido os resultados da pesquisa, além disso, foram compartilhadas dicas para facilitar o processo de implantação da coleta seletiva, sendo muitas delas apresentadas pelos próprios gestores ambientais em suas respostas.

Palavras-chave: Coleta seletiva; Resíduos sólidos urbanos; Gestão ambiental; Educação ambiental

\section{Abstract}

There are still insufficient Brazilian municipalities which carry out actions for the urban solid waste management. Several factors have contributed to environmental education work in many cases being absent or ineffective. This study aimed to identify the methods of environmental education, the weaknesses and potentialities in the system implementation process, aiming at analysis, discussion and proposition of tools, solutions and/or mitigation of the difficulties which were found. For this, a qualitative and quantitative research was conducted directed to the environmental managers of the municipalities of the northwestern Rio Grande do Sul-RS. Given the results it was found that many municipalities are still late in this process and the vast majority have faced numerous challenges, including the lack of support within the municipal administration and the general population. It was also evidenced the necessity of the implantation of this system to be intense and uninterrupted, integrating information activities, sensitization and mobilization of all involved. After data analysis, a lecture was realized with the environmental managers, where the research results were presented and discussed. In addition, tips were shared to facilitate the process of implementing selective collection, many of which were presented by the environmental managers themselves in their responses.

Keywords: Selective collect; Urban solid waste; Environmental management; Environmental education 


\section{Introdução}

Considera-se que os impactos negativos sobre o meio físico e social advêm, primordialmente, do comportamento das populações, instigado em sua maioria por interesses capitalistas desenfreados, os quais não primam pelo desenvolvimento sustentável e acabam por sobrecarregar o planeta. Como resultados, percebe-se a crescente demanda por recursos naturais, geralmente não renováveis, o esgotamento dos mananciais, a poluição de vários tipos e, o que aqui dá-se destaque, a geração excessiva de resíduos sólidos.

O desenvolvimento considerado durante muito tempo um valor universalmente aceito, e meta de toda sociedade moderna, hoje é questionado, inclusive sobre a forma como é produzido, este, coloca em risco a estabilidade dos ecossistemas terrestres. Para Stumpf (2018), a geração de resíduos sólidos apresenta-se como aspecto indissociável do processo industrial, neste sentido, para alcançar o equilíbrio ambiental demandará investimentos e tecnologias para a adequada destinação final destes resíduos e a busca pela almejada sustentabilidade.

Nogueira (2014) confirma que problemática da política de gerenciamento de resíduos sólidos reside na busca pelo consumo desenfreado, mas também sugere um revés nas questões culturais, educacionais e éticas da sociedade no aspecto conceitual de "lixo". Pelo próprio conceito de lixo, dá-se a ideia que se trata de algo que não se tem valor ou utilidade e impossível de ser reaproveitado, no entanto, a denominação "resíduos sólidos” remete a materiais que, se gerenciados corretamente, podem ser aproveitados tanto para sua reutilização quanto para a reciclagem.

No Brasil, foi sancionada em agosto de 2010 a lei $n^{\circ}$ 12.305, denominada de Política Nacional de Resíduos Sólidos (PNRS). A mesma é considerada um marco apresentando importantes instrumentos visando o desenvolvimento sustentável, a inclusão social e a gestão integrada, tais como a necessidade de planos municipais, escala de prioridades de estratégias (não geração, redução, reutilização e reciclagem), bem como a coleta seletiva e a educação ambiental, sendo o gerenciamento dos resíduos sólidos urbanos (RSU) um parâmetro importante para a qualidade de vida dos brasileiros. Em seu art. 18, a PNRS já define a obrigatoriedade dos municípios brasileiros de elaborarem e implantarem seus planos municipais de gestão integrada (PMGIRS), inclusive de programas de coleta seletiva (PCS), requisito para obterem acesso a recursos da união (BRASIL, 2010).

Apesar disto, muitos municípios ainda não implantaram o sistema de coleta seletiva em sua gestão ou ainda estão em fase inicial de implantação, conclui-se então que a realidade das problemáticas ambientais dos municípios é extremamente complexa, envolvendo em sua essência questões de caráter social, econômico, político e cultural, e deve ser encarada de forma ampla, conjugando esforços nas mais diferentes frentes de atuação, para que as transformações almejadas tornem-se realidade.

Na Política Nacional de Resíduos Sólidos, a coleta seletiva e a reciclagem são instrumentos-chave para a implantação da responsabilidade compartilhada pelo ciclo de vida dos produtos, além de ser fundamental para viabilizar a hierarquização no gerenciamento dos resíduos e a inclusão socioeconômica dos catadores. Neste sentido, a diretriz da PNRS estabelece que a coleta seletiva deve ser amplamente considerada nos planos, devendo ser criados instrumentos para sua viabilização.

De maneira geral, a coleta seletiva se fundamenta em três etapas, o qual envolvendo a educação ambiental onde é feita a transmissão de informação para motivação da população, a separação dos resíduos e por fim a coleta e envio às recicladoras. Em termos de logística, é necessária a disponibilidade de mão-de-obra e veículos necessários para efetuar a coleta, uma central de triagem, ou seja, uma estrutura (de preferência um pavilhão fechado) com boxes para a armazenagem dos materiais separados, além de prensas para o enfardamento do material, esteiras de segregação e local para estocagem. O fato é que a significativa presença de matéria orgânica em decomposição, encontrada nos resíduos domiciliares, determina a necessidade de transporte ágil e destinação imediata.

Nos termos do que dispõe o artigo $2^{\circ}$, estão sujeitos à observância da Política Nacional de Resíduos sólidos as pessoas físicas ou jurídicas, de direito público ou privado, responsáveis, direta ou indiretamente, pela geração de resíduos sólidos e as que desenvolvam ações relacionadas à gestão integrada ou ao gerenciamento de resíduos sólidos (BRASIL, 2010).

O manejo dos resíduos sólidos depende de vários fatores, dentre os quais devem ser ressaltados: a forma de geração, acondicionamento na fonte geradora, coleta, transporte, processamento, recuperação e disposição final. Portanto, deve-se criar um sistema dirigido pelos princípios de engenharia e técnicas de projetos, que possibilite a construção de dispositivos capazes de propiciar a segurança sanitária às comunidades, contra os efeitos adversos dos resíduos e a viabilização dos mesmos a serem reciclados (SCHALCH et al., 2012).

De acordo com o Instituto de Pesquisa Econômica Aplicada (2012), um grande desafio para a implementação e o cumprimento das diretrizes da PNRS é, justamente, promover a mudança de cultura da população, de forma que extrapolem a conduta negligente ou reativa, passando a assumir uma conduta mais responsável, caracterizada por uma abordagem mais proativa.

A PNRS apresenta diferentes problemas para sua efetiva aplicação, entre os quais se destacam a baixa disponibilidade orçamentária e a fraca capacidade institucional e de gerenciamento de muitos municípios brasileiros, especialmente os de pequeno porte (HEBER e SILVA, 2014). Para enfrentar esses desafios, essa lei estabelece diretrizes de gestão compartilhada, como a formação de consórcios intermunicipais de gerenciamento dos resíduos sólidos, alternativa esta, adotada pelos municípios analisados no presente estudo através do Consórcio Intermunicipal de Gestão de Resíduos SólidosCIGRES.

O CIGRES é uma unidade de triagem que tem a missão de receber os resíduos sólidos (domésticos), 
gerado pelos municípios consorciados, fazer uma correta separação (triagem) deste material, tratá-lo de forma correta e acondicioná-lo adequadamente visando criar uma alternativa economicamente viável e ambientalmente correta, trazendo economia para as administrações municipais e qualidade de vida para a população (CIGRES, 2018).

A educação ambiental também é uma ferramenta chave e de uso indispensável para que todo este processo se torne viável, contribuindo para o desenvolvimento de habilidades, permitindo a modificação de atitudes em relação ao meio ambiente. Esta visa despertar a preocupação individual e coletiva para a questão ambiental através da construção de valores sociais, atitudes e competências voltadas para a conservação do meio ambiente. Pode ainda contribuir para mudar o comportamento do homem com relação à natureza, com o objetivo de atender às necessidades ativas e futuras, no sentido de promover um modelo de desenvolvimento sustentável (VIANA et al. 2016).

O conceito de Educação Ambiental é definido na Política Nacional de Educação Ambiental - PNEA, Artigo 1․: "trata-se da construção de valores, conhecimentos, habilidades, atitudes e competências voltadas para a conservação ambiental, praticando um bem social comum, necessário para a sustentabilidade e qualidade de vida" (BRASIL, 1999, $\operatorname{art.1}{ }^{\circ}$ ). A legislação ainda aponta que a educação ambiental é capaz de formar cidadãos críticos e conscientes dos problemas ambientais encontrados, contribuindo para a preservação e conservação do meio ambiente urbano, pois os conduzem a exigirem políticas públicas mais eficientes para o alcance do equilíbrio do ecossistema como um todo, o qual deverá se manter sadio para o uso das gerações que ainda estão por vir (BRASIL, 1999).

$\mathrm{Na}$ tentativa de analisar o programa de coleta seletiva dos municípios consorciados ao CIGRES e entender os inúmeros problemas encontrados pelos gestores/ educadores ambientais neste processo de implantação da coleta seletiva, apresenta-se este estudo, o qual propõem instrumentos para a solução e/ou mitigação das dificuldades encontrada, além disso, o mesmo surge como um incentivador para que os futuros gestores entendam melhor este processo colaborando assim com esta temática ambiental.

\section{Metodologia}

\subsection{Tipo de Pesquisa}

Trata-se de um estudo de caso realizado através de uma pesquisa quali-quantitativa, feita por meio de um questionário semi-aberto com 23 questões. Desse modo, tornou-se possível que a pesquisa apresentasse uma parte quantitativa com coleta de dados, tabulações e análise estatística através de questões fechadas e ao mesmo tempo apresentar espaços para respostas subjetivas, flexíveis e de múltiplas interpretações possibilizando uma análise de características mais complexas e não- quantificáveis, como o comportamento, as expressões, os sentimentos, etc.

\subsection{Participantes do Estudo}

A pesquisa foi direcionada aos gestores ambientais municipais dos 31 municípios da região noroeste do Rio Grande do Sul participantes do Consorcio Intermunicipal de Gerenciamento de Resíduos Sólidos- CIGRES, sendo eles: Ametista do Sul, Barra do Guarita, Boa Vista das Missões, Caiçara, Cerro Grande, Cristal do Sul, Derrubadas, Dois Irmãos das Missões, Erval Seco, Frederico Westphalen, Iraí, Jaboticaba, Lajeado do Bugre, Liberato Salzano, Miraguaí, Novo Tiradentes, Palmitinho, Pinhal, Pinheirinho do Vale, Planalto, Redentora, Rodeio Bonito, Sagrada Família, São José Das Missões, São Pedro das Missões, Seberi, Taquaruçu do Sul, Tenente Portela, Vicente Dutra, Vista Alegre e Vista Gaúcha.

\subsection{Local do Consórcio}

O Consórcio Intermunicipal de Gestão de Resíduos Sólidos - CIGRES localiza-se no Rio Grande do Sul no município de Seberi, BR 386, km 43, linha Osvaldo Cruz. O consórcio foi criado como uma alternativa para atender a região e seus municípios no que diz respeito a resíduos sólidos urbanos e viabilizar a implantação de novos programas e tecnologias que possam apoiar o desenvolvimento sustentável voltado à proteção do meio ambiente à busca pela qualidade de vida da população (CIGRES, 2018

O CIGRES Teve sua constituição no dia 14 de setembro de 2001, e com apoio do Ministério do Meio Ambiente, através do Fundo Nacional do Meio Ambiente (FNMA), o qual repassou recursos financeiros para constituição do mesmo, e também contrapartida dos municípios. Teve inicio da aplicação do recurso no ano de 2005, iniciando sua operação em 12 de março de 2007 (CIGRES, 2018). Atualmente, o consórcio é formado por 31 municípios, todos pagam mensalmente ao consórcio valores individuais conforme o peso e a qualidade dos resíduos encaminhados.

\subsection{Análise dos Dados}

Para as questões fechadas do questionário foi realizada a quantificação dos dados, tabelas, quadros e gráficos. As questões abertas foram analisadas e interpretadas, para posterior discussão. O pesquisador é o instrumento-chave neste processo, o ambiente é a fonte direta dos dados, não requer o uso de técnicas e métodos estatísticos, têm caráter descritivo, o resultado não é o foco da abordagem, mas sim o processo e seu significado, ou seja, o principal objetivo é a interpretação do fenômeno objeto de estudo.

\subsection{Ação Ambiental}

Dados os resultados da pesquisa, reuniu-se com os gestores ambientais dos municípios consorciados ao CIGRES e também com a equipe técnica e diretiva do 
consórcio (Figura 1) para a apresentação dos resultados. $\mathrm{Na}$ oportunidade foi dialogado e debatido sobre o processo de implantação do sistema de coleta seletiva municipal na prática, ouve trocas de experiência entre os participantes, exposição de ações eficazes e proposição de medidas mitigatórias para as dificuldades encontradas.

\section{Figura 1 - Apresentação dos resultados da pesquisa aos gestores ambientais dos 31 municípios consorciados ao CIGRES}

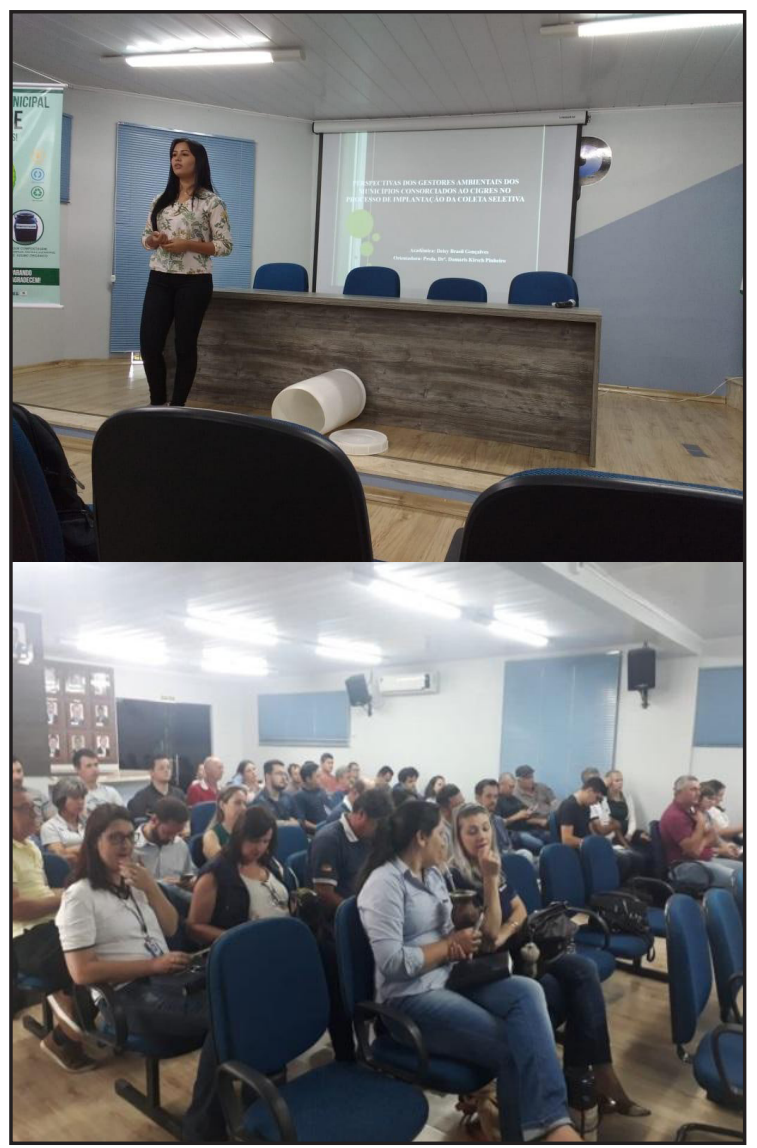

Fonte: A autora

\section{Resultados e Discussões}

Dos 31 municípios participantes do CIGRES, dois municípios não quiseram participar da pesquisa. $O$ gestor de um deles afirmou apenas que não haviam implantado a coleta seletiva e que não iria responder o questionário. $\mathrm{O}$ outro gestor foi mais minucioso em sua resposta, segue ela na integra: "Havíamos iniciado a campanha da coleta seletiva, nos envolvemos a mais de 1 ano, num projeto de capacitação dos agentes envolvidos diretamente com a divulgação porta a porta, que foi feito pela agentes de saúde, fizemos notas na radio, cartilhas, panfletos, organizado, rotas, pré-organizada/mapeada a cidade, treinamentos, palestras, teatros, enfim tínhamos (nós do meio ambiente) tudo encaminhado para fazer um ótimo trabalho e ter muito sucesso na implantação da coleta seletiva no município, inclusive havíamos estipulado uma data de inicio de fato. No entanto, nas vésperas do inicio da mesma (que alias já estava sendo divulgada), por ordem da administração municipal (mais especificamente do vice prefeito, que estava em exercício na época) foi cancelado tudo, justificado pela falta de ajustes do contrato com a empresa recolhedora e outras coisa que ele achava ser mais importante que a coleta seletiva e, até a presente data, não tivemos retorno ou manifestação de apoio para retomada. Por isso, não achei conveniente responder ao questionário, pois muitas das perguntas não iriam condizer com a realidade, pois no papel está uma coisa e na prática é outra. Agradeço pela compreensão".

Além deste caso, em que o gestor nem quis participar da pesquisa, notou-se mais casos como este. No questionário havia uma pergunta específica em relação a este aspecto, ou seja, questionava se os departamentos e secretarias ambientais representadas pelos responsáveis pela implantação da coleta seletiva haviam recebido apoio da administração na implantação da coleta seletiva. Um gestor foi objetivo em afirmar não terem recebido apoio da administração municipal: "Não recebemos, o setor de meio ambiente não tem estrutura necessária e nem profissionais para exercer essa demanda". Outros três disseram ter recebido pouco apoio, "Justificam que aumentando os dias de coleta, aumentam os custos com o caminhão terceirizado"; "Parcialmente, conseguimos o transporte duas vezes na semana, porém gostaríamos de investimento para fazer a compostagem e até agora nada!; "encontramos apoio em partes, a resistência ainda é observada pois os gestores administrativos não conseguem identificar a importância da coleta seletiva de resíduos, estão implantando apenas por obrigação”.

O restante dos gestores responsáveis pela coleta seletiva afirmou receber apoio de forma satisfatória da administração, disponibilizando funcionários, verbas, como participantes ativos do planejamento e na divulgação da coleta seletiva. Entre algumas falas destaca-se: "O setor de meio ambiente encontra apoio da administração municipal, pois a mesma está conscientizada da importância das questões relacionadas ao meio ambiente"; "Sim, foi comprada algumas lixeiras para suprir as necessidades do período urbano e conteiners... Apoio também para a divulgação no interior, coleta e transporte"; "Sim, houve apoio da administração em toda e qualquer ação que foi desenvolvida pela equipe, principalmente com recursos financeiros para a confecção de cartilhas e folders, dentro do possivel com recursos humanos também, pois como não existe profissionais exclusivos para este setor, foi realizado ações em conjunto para atingir os objetivos."; "Sim, a administração municipal forneceu apoio desde antes da implantação da coleta seletiva na rota central (projeto piloto), com a divulgação na imprensa e organização de audiências públicas relacionada a essa pauta. Posteriormente, a administração forneceu a mão de obra necessária a demanda dos dias alternados do recolhimento.”.

Quanto a formação dos gestores entrevistados, um possui nível superior incompleto, quatro possuem formação tecnóloga sendo elas três técnicos agrícola e um em gestão pública, os outros todos possuem nível superior sendo dez formados em ciências biológicas ou biologia, quatro engenheiros ambientais e sanitaristas, um engenheiro florestal, dois em agronomia, um em administração e um assistente social. Nota-se que a grande maioria está qualificada para a função desta grande responsabilidade que é a implantação e manutenção da coleta seletiva municipal, porém pode-se notar que algumas qualificações fogem da área ambiental, o que poderá tornar 
este processo mais difícil, visto que o processo de educação ambiental é complexo e requer pessoas que entendam cada etapa e que amem realmente esse ofício, sobretudo que estejam dispostas a lutar pela causa.

Conforme disposto no Quadro 1, o cargo variou muito entre os responsáveis pela coleta seletiva dos 29 municípios que participaram da pesquisa, não se apresentou um padrão e em todos os casos, identificouse que o cargo não é específico para essa atividade, ou seja, é apenas uma função atribuída ao mesmo.

Analisando o quadro de funcionários (Quadro 2) evidencia-se que poucos municípios possuem uma secretaria de meio ambiente, sendo que, praticamente todas estão elencadas à secretaria da agricultura. Além disso, constatou-se que, em muitos casos, não possuem funcionários próprios, ou seja, funcionários da agricultura são designados a atender as questões ambientais do município.

Em um caso específico em que não se estava conseguindo obter a resposta para o questionário por e-mail, tevese que ir pessoalmente à secretaria da agricultura do município, e pode-se comprovar a desordem da mesma. Um dos funcionários usou a palavra "caos" para definir o departamento ambiental, afirmou também que era um colega da secretaria da agricultura que era responsável pela parte ambiental e que o mesmo estava atarefado no momento, sendo assim a responsabilidade da coleta seletiva estava a cargo do secretário da administração, o qual não tinha formação alguma para desenvolver a temática ambiental de educação. Em outro caso, a secretaria ou departamento ambiental se quer existe, sendo assim, quem responde é um auxiliar administrativo com formação em gestão ambiental.

Relacionado a quanto tempo está no cargo, conforme a Tabela 1, as respostas também variaram. Destaca-se os que estão à menos de 3 anos nos cargos com cerca de $55 \%$ dos entrevistados. Para Arthur Guimarães (2008) isso torna-se um obstáculo para as atividades de educação ambiental, visto que a educação é um processo contínuo e ininterrupto, sugerindo que este fato é devido a descontinuidade política, resultante das mudanças nas secretarias as quais passam por "muitas mãos".

A Política Nacional de Resíduos Sólidos - PNRS (Lei n⿳ 12.305/2010) estabelece em seu art. $8^{\circ}$ um rol de instrumentos necessários para o alcance dos objetivos da política, sendo que os planos de resíduos sólidos são um dos principais e mais importantes instrumentos. Quando questionados sobre o plano municipal, dos 29 municípios que responderam o questionário, 27 possuem o plano, um está em fase de elaboração e um não possui o mesmo (Gráfico 1).

Segundo o Ministério do Meio Ambiente, os planos de resíduos sólidos devem abranger o ciclo que se inicia desde a geração do resíduo, com a identificação do ente gerador, até a disposição final ambientalmente adequada dos rejeitos, passando pela responsabilização do setor público, titular ou concessionário, do consumidor, do cidadão e do setor privado na adoção de soluções que minimizem ou ponham fim aos efeitos negativos para a saúde pública e para o meio ambiente em cada fase do "ciclo de vida" dos produtos.

Quadro 1 - Cargo dos gestores/educadores ambientais responsáveis pela implantação da coleta seletiva municipal

\begin{tabular}{|c|c|}
\hline Cargo ou Função & Quantidade \\
\hline Licenciador Ambiental & 4 \\
\hline Biólogo & 3 \\
\hline Tec. em Agropecuária/Agrícola & 3 \\
\hline Extensionista Rural & 1 \\
\hline Secretário do Meio Ambiente & 2 \\
\hline Secretário da Agricultura/adjunto & 3 \\
\hline Secretário da Administração & 1 \\
\hline Assistente Social Nasf & 1 \\
\hline Agente Administrativo & 1 \\
\hline Fiscal Ambiental & 4 \\
\hline Coordenador Ambiental & 1 \\
\hline Encarregado de Meio Ambiente & 1 \\
\hline Diretor de Programa da Sec. De Agricultura e Meio Ambiente & 1 \\
\hline Analista Ambiental & 1 \\
\hline Prestador de serviço & 1 \\
\hline Coordenador de Licenciamento e Fiscalização & 1 \\
\hline TOTAL & $29^{*}$ \\
\hline
\end{tabular}

Fonte: Autora (2018)

* Número total de municípios que participaram da pesquisa 
Quadro 2 - Quadro de funcionários dos departamentos e secretarias de meio ambiente dos municípios consorciados ao CIGRES que participaram da pesquisa.

\begin{tabular}{|c|c|}
\hline Município & Funcionários do Departamento ou Sec. de Meio Ambiente \\
\hline 1 & 1 Fiscal ambiental e 1 Licenciador ambiental \\
\hline 2 & 1 analista ambiental, 1 Fiscal ambiental e assessoria de empresa de consultoria ambiental. \\
\hline 3 & 1 licenciador, 1 Fiscal e empresa de assessoria de empresa de consultoria ambiental. \\
\hline 4 & 1 Coordenador de Licenciamento e Fiscalização e um fiscal ambiental. \\
\hline 5 & $\begin{array}{c}1 \text { engenheiro agrônomo, } 1 \text { agente administrativo, } 1 \text { fiscal ambiental e assessoria de empresa de } \\
\text { consultoria ambiental. }\end{array}$ \\
\hline 6 & 1 Biólogo e 1 Fiscal. \\
\hline 7 & Assessoria de empresa de consultoria ambiental e 1 funcionário (não especificou qual). \\
\hline 8 & 2 técnicos agrícolas e assessoria de empresa de consultoria ambiental. \\
\hline 9 & 1 biólogo \\
\hline 10 & 2 Funcionários (não especificados) e um estagiário. \\
\hline 11 & 1 Licenciador Ambiental, 1 Fiscal ambiental/sanitário e Secretário da agricultura e meio ambiente. \\
\hline 12 & 1 Coordenador do meio ambiente, 1 assistente social. \\
\hline 13 & 1 Biólogo, 1 Fiscal e assessoria de empresa de consultoria ambiental. \\
\hline 14 & 1 licenciador e 1 Fiscal (profissionais da sec. da agricultura com atribuições) \\
\hline 15 & Não possui. Quem responde é um auxiliar administrativo com formação em gestão ambiental. \\
\hline 16 & 1 Licenciador e 1 fiscal \\
\hline 17 & 1 Licenciador e 1 fiscal \\
\hline 18 & 1 Licenciador e 1 diretor de programa \\
\hline 19 & 4 funcionários (não especificados) e 1 estagiário \\
\hline 20 & Não possui funcionário específico do departamento (os da sec. da agricultura que respondem). \\
\hline 21 & 5 funcionários não especificados entre sec. da agricultura e meio ambiente. \\
\hline 22 & 1 Bióloga e secretária. \\
\hline 23 & 1 licenciador e 1 fiscal ambiental. \\
\hline 24 & 1 Biólogo licenciador e 1 fiscal/técnico agrícola. \\
\hline 25 & 1 Secretário, 1 atendente, 1 Engenheira florestal e 1 fiscal. \\
\hline 26 & 1 licenciador ambiental 1 fiscal ambiental \\
\hline 27 & 1 Fiscal ambiental, 1 biólogo terceirizado, 1 licenciador. \\
\hline 28 & 1 fiscal ambiental e e técnicos agrícolas \\
\hline 29 & 1 funcionário (não especificado) \\
\hline
\end{tabular}

Fonte: Autora (2018) 
Tabela 1 - Tempo que os gestores/educadores estão nos cargos

\begin{tabular}{lcc}
\hline \multicolumn{1}{c}{ Tempo na função } & $\begin{array}{c}\text { Gestores/ } \\
\text { educadores }\end{array}$ & Porcentagem \\
\hline 1 ano ou menos & 7 & $24 \%$ \\
2 anos & 5 & $17 \%$ \\
3 anos & 4 & $14 \%$ \\
4 anos & 1 & $3 \%$ \\
5 anos & 2 & $7 \%$ \\
6 à 10 anos & 7 & $24 \%$ \\
11 à 20 anos & 1 & $3 \%$ \\
Mais que 20 anos & 2 & $7 \%$ \\
Total & 29 & $100 \%$ \\
\hline
\end{tabular}

Fonte: Autora (2018)

Figura 1 - Situação dos municípios em relação ao plano municipal de resíduos sólidos.

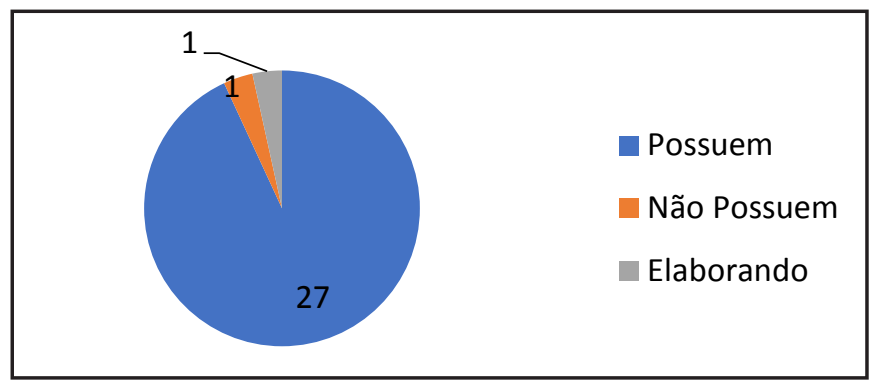

Fonte: Autora (2018)

Uma questão relevante a se destacar é que dos municípios que possuem o plano, $84 \%$ diz estar atingindo parcialmente as metas dos planos (Tabela 2), o que é um número elevado, apenas $16 \%$ diz estar atingindo todas as metas, dois municípios aprovaram recentemente o plano e ainda não possuem esse dado de sucesso ou insucesso do mesmo. Este resultado sugere que é devido a recente implantação da coleta seletiva nos mesmos, sendo assim os resultados ainda são insatisfatórios.

De acordo com a Política Nacional de Resíduos Sólidos, a implantação da coleta seletiva é obrigação dos municípios e metas referentes à coleta seletiva fazem parte do conteúdo mínimo que deve constar nos planos de gestão integrada de resíduos sólidos dos municípios. Dos 31 municípios consorciados ao CIGRES, 12 ainda não implantaram a coleta seletiva, desses, seis estão em fase inicial de planejamento, sendo que alguns já iniciaram a fase de divulgação e educação ambiental (Tabela 3), 19 munícipios implantaram efetivamente a coleta seletiva, a maioria com início no ano de 2017, alguns em 2018, mas vale destacar que um município iniciou em 2012 e dois em 2014, o que mostra o real interesse e empenho dos gestores neste trabalho.

Entre os motivos que os gestores deram para ainda não terem implantarem o sistema foi ao fato da lei municipal de implantação não ter sido aprovada até o momento da pesquisa, a falta de apoio da administração, falta de interesse dos envolvidos, entre outros.

Segundo estimativas do IPEA (2013), apenas 2,4\% de todo o serviço de coleta de resíduos sólidos urbanos no Brasil são realizados de forma seletiva, sendo todo o restante realizado como coleta regular, na qual se misturam e se compactam todos os materiais conjuntamente, dificultando ou até mesmo impossibilitando a reutilização/ reciclagem de parte destes materiais. Apesar de a porcentagem de implementação da PNRS dentre os municípios participantes do consórcio ser superior a $60 \%$, considera-se este índice baixo, pois a meta é os $100 \%$.

Para Oliveira (2011), esses baixos índices observados de coleta seletiva devem-se ao fato de envolver uma série de desafios que dificultam sua implementação, uma vez que é preciso levar em conta aspectos sanitários, ambientais, ecológicos, demográficos, administrativos, políticos, culturais, sociais e econômicos. Por conseguinte, programas de coleta seletiva exigem um complexo planejamento para terem real viabilidade de maneira sustentável, evitando, assim, descontinuidades ou mesmo sua interrupção, vale ressaltar que a limpeza pública, incluindo a coleta seletiva é um serviço oneroso, onde são consumidos entre 10 e $15 \%$ de todo o orçamento dos municípios (LEITE, 1995 apud SCHALCH et. al, 2012).

Quando questionados se a população estava colaborando com o sistema, dos 19 que já implantaram o sistema, dois municípios disseram que sim, um disse que não e o restante disse que parcialmente.

O comentário principal acerca destas afirmações foi que parte da população ainda não separa corretamente ou que troca os dias de recolhimento de cada resíduo, que há uma geração excessiva de resíduos. Destacou-se também a falta de compostagem para os resíduos orgânicos os quais pesam mais e acaba gerando um custo maior ao município. Um gestor ainda citou que alguns munícipes não tomavam cuidado com o descarte de materiais perigosos. Outro falou que alguns colocam muito peso nas sacolas e que acabam estourando, destacou também a disposição para o recolhimento errada, feita após ou muito antes da coleta. Em falas de dois gestores nota-se a expressiva decepção com a resistência dos munícipes: "Encontramos bastante resistência por parte da população, a maioria das pessoas recebem de forma positiva as orientações para a correta separação domésticas de resíduos, porém não a fazem. O processo da coleta seletiva exige uma mudança de hábitos, o que demanda tempo, exigindo insistência em ações de conscientizações"; "Dificuldade de formar as pessoas capazes de refletir sobre o assunto, compreender que o problema do lixo não acaba na frente de sua casa, continua após o recolhimento, que são pessoas como nós que fazem a triagem manualmente, enfim, falta de amor e respeito ao próximo".

Dos 19 municípios que possuem a coleta seletiva implantada, dois separam em secos e orgânicos, e o restante em secos, orgânicos e rejeitos. Nos que não implantaram a coleta seletiva ou que estão em fase inicial de implantação, os resíduos ainda são dispostos misturados. 
Tabela 2 - Porcentagem de municípios em relação às metas dos planos municipais de resíduos sólidos

\begin{tabular}{lcc}
\hline \multicolumn{1}{c}{ Situação } & $\begin{array}{c}\text { Número de } \\
\text { municípios }\end{array}$ & Porcentagem \\
\hline Atingindo & 4 & $14,81 \%$ \\
Não Atingindo & 0 & $0 \%$ \\
Parcialmente & 21 & $77,78 \%$ \\
$\begin{array}{l}\text { Em fase inicial de } \\
\text { implantação (sem este } \\
\text { dado) }\end{array}$ & 2 & $7,41 \%$ \\
Total & 25 & $100 \%$ \\
\hline
\end{tabular}

Fonte: Autora (2018)

Tabela 3 - Situação dos munícipios em relação à implantação da coleta seletiva

\begin{tabular}{lcc}
\hline Fase do processo & $\begin{array}{c}\text { Número de } \\
\text { municípios }\end{array}$ & Porcentagem \\
\hline Implantaram & 19 & $61,3 \%$ \\
Não Implantaram & 6 & $19,4 \%$ \\
Em fase inicial & 6 & $19,4 \%$ \\
Total & $31^{*}$ & $100,0 \%$ \\
\hline
\end{tabular}

Fonte: Autora (2018)

* Os dois municípios que não participaram da pesquisa afirmaram que não haviam implantado o sistema, totalizando assim os 31 municípios do consórcio.

Um dos pontos de maior importância na implantação da coleta seletiva é o planejamento dos dias de coleta e do tipo de resíduos que serão recolhidos. Esse fator variou consideravelmente entre os municípios (Quadro 3), o que se julga normal, pois cada município possui uma realidade diferente. Por exemplo, existem munícipios que incentivam muito a compostagem, sendo assim, este teria um menor índice de geração de resíduos orgânicos, podendo este tipo de resíduo ter um número de recolhimento semanalmente. Outro fator relevante são recursos disponíveis. Sabe-se que a coleta de resíduos é onerosa, e aumentar dias para a coleta ou disponibilizar mais caminhões em muitos casos é inviável para certos municípios. Por isso, nota-se que em alguns municípios os resíduos (secos e orgânicos) e rejeitos são coletados no mesmo dia, o que não seria o ideal, pois poderá o orgânico e o rejeito inviabilizar a reciclagem ou diminuir o valor dos resíduos recicláveis, a não ser que o caminhão seja dividido ao meio e não ocorra o contato dos resíduos secos com o restante, sendo assim, este método não alteraria a viabilidade da reciclagem.

Outro fator para análise é se a cidade apresenta catadores de materiais recicláveis. Dos 29 municípios que responderam a pesquisa, 20 não possuem catadores de materiais recicláveis, nove possuem. Segundo o MMA (2013), os catadores de matérias reutilizáveis e recicláveis desempenham papel fundamental na implementação da Política Nacional de Resíduos Sólidos (PNRS), com destaque para a gestão integrada dos resíduos sólidos. De modo geral, atuam nas atividades da coleta seletiva, triagem, classificação, processamento e comercialização dos resíduos reutilizáveis e recicláveis, contribuindo de forma significativa para a cadeia produtiva da reciclagem, atuando como verdadeiros agentes de difusão de conhecimentos sobre a coleta seletiva. Porém, deve-se ficar atento que, na maioria dos casos, esses catadores encontram-se irregulares. Essa perspectiva no ponto de vista econômico do município e do consórcio não é válida, pois os materiais recicláveis são dotados de valor, sendo assim é vantagem mandar ao CIGRES, pois o município recebe um abono do valor total que paga ao consórcio.

Alguns tipos de resíduos sólidos são altamente perigosos para o meio ambiente, podendo causar a contaminação do solo no local do despejo ou até mesmo de grandes áreas caso entrem em contato com algum riacho ou até mesmo algum lençol freático. Esse tipo de material perigoso requer um sistema de coleta, classificação, tratamento e descarte diferenciado, adequado e rigoroso.

Pode-se citar como exemplos as pilhas e baterias de telefones e equipamentos eletrônicos que são formados por compostos químicos com alta capacidade de poluição e toxicidade para o solo e a água, os quais são também extremamente tóxicos aos seres humanos e animais. Esse tipo de material deve ser tratado com muita cautela durante os processos de coleta seletiva. Orienta-se fazer pontos de coleta ou campanha de recolhimento para esses tipos de materiais, onde as pessoas possam descartálos, para que depois sejam coletados por empresas especializadas na sua destinação.

Quando questionados se os municípios faziam essas campanhas de recolhimento diferenciadas de material eletrônicos, entre outros, 17 municípios afirmaram realizar para resíduos eletrônicos e dois municípios para resíduos industriais. Além disso, alguns afirmaram fazer campanha de recolhimento para Pilhas e baterias (anual) lâmpadas (semestral) óleo de cozinha (ponto de coleta)

Implantar um sistema de coleta seletiva não é uma tarefa fácil, pois são necessárias diversas etapas para conseguir maximizar resultados, minimizar custos de implantação e conseguir atender as expectativas, ou seja, para que a coleta seletiva seja colocada em prática, é preciso incentivar a implantação de projetos que visem à estruturação e divulgação. Todavia, de fato enfrentamse dificuldades relacionadas: à organização interna do trabalho; recursos, aos tipos de resíduos coletados, alguns dos quais não são recicláveis e têm que ser descartados; com a falta de lixeiras e caminhões adequados, falta de funcionários, falta de apoio dos envolvidos; com a concorrência de catadores que passam nos bairros coletando os materiais antes dos cooperados, entre outras dificuldades.

Do ponto de vista dos gestores, a falta de colaboração dos munícipes é o maior impedimento para o sucesso da implantação da coleta seletiva (Figura 2). Outros dois municípios citaram a falta de caminhão adequado como uma dificuldade e outro citou a falta de logística para o recolhimento, ressalta-se que, a logística é responsabilidade do próprio município. 
Para o sistema de coleta seletiva ter sucesso, é necessário que a população tenha consciência do projeto. Uma das alternativas constitui-se em ampliar a divulgação da coleta seletiva e conseguir maior adesão das comunidades. Elaborar um plano para sensibilizar os moradores das vantagens da coleta seletiva. Isso pode ser feito através de palestras, cartazes informativos, manuais de coleta seletiva. O importante é mostrar que a coleta seletiva, atualmente, é algo fácil, além de vantajoso, mas que requer empenho e disciplina, que como toda mudança é difícil, mas que sem dúvida é uma mudança para o melhor de todos.

Para que a implantação de um programa de coleta seletiva obtenha o êxito esperado, é necessário que os participantes estejam sensibilizados e conscientizados quanto à maneira certa de manusear os resíduos, desde o descarte no coletor até a armazenagem dos resíduos antes de seguir para a reciclagem. É importante que a população saiba da realidade, do consórcio, principalmente do processo de triagem, pois são seres humanos que estão sob condições muitas vezes adversas. Quando questionados se a população tinha conhecimento para onde iam seus resíduos, 20 gestores afirmaram que uma grande parte da população sabia, dois afirmaram que apenas uma pequena parte tinha conhecimento, e cinco gestores foram convictos de que toda a população tem conhecimento.

Diferentes caminhos de sensibilização e engajamento das pessoas na questão ambiental/ ecológica implicam ampla diversidade de atividades e propostas de processos educacionais voltados para ela. Quando questionados em relação aos recursos utilizados para este trabalho, as atividades em destaque foram panfletos, divulgação em rádio e divulgações nas escolas, além das atividades expostas no Figura 3. Outras foram citadas como Imãs e flyer, audiência pública, reuniões, mobilizações com as agentes comunitárias de saúde, integração com outros setores (Emater), cultos e missas.

Visto a variedade de propostas e recursos dispostos para a educação ambiental e dentro da perspectiva e realidade de cada município, procurou-se identificar quais atividades não tiveram um resultado satisfatório ou que não deram certo e quais obtiveram sucesso dentro

Figura 2 - Dificuldades enfrentadas na implantação da coleta seletiva

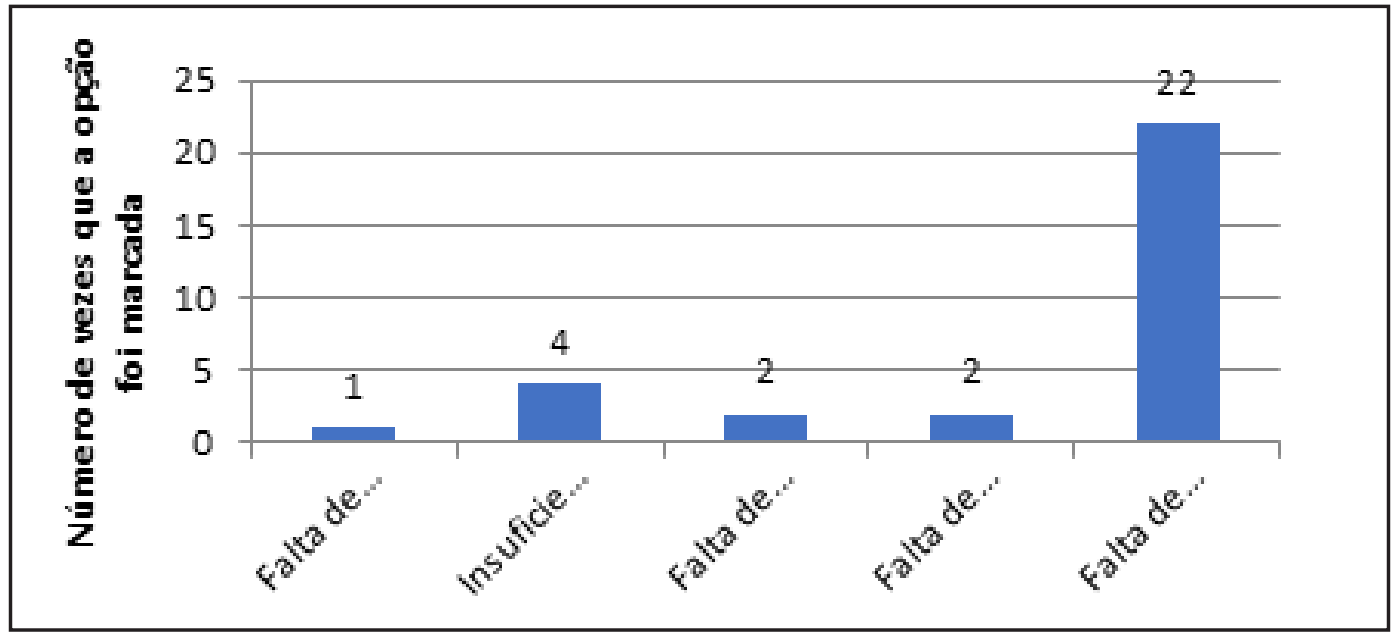

Fonte: Autora (2018)

Figura 3 - Recursos utilizados na implantação da coleta seletiva

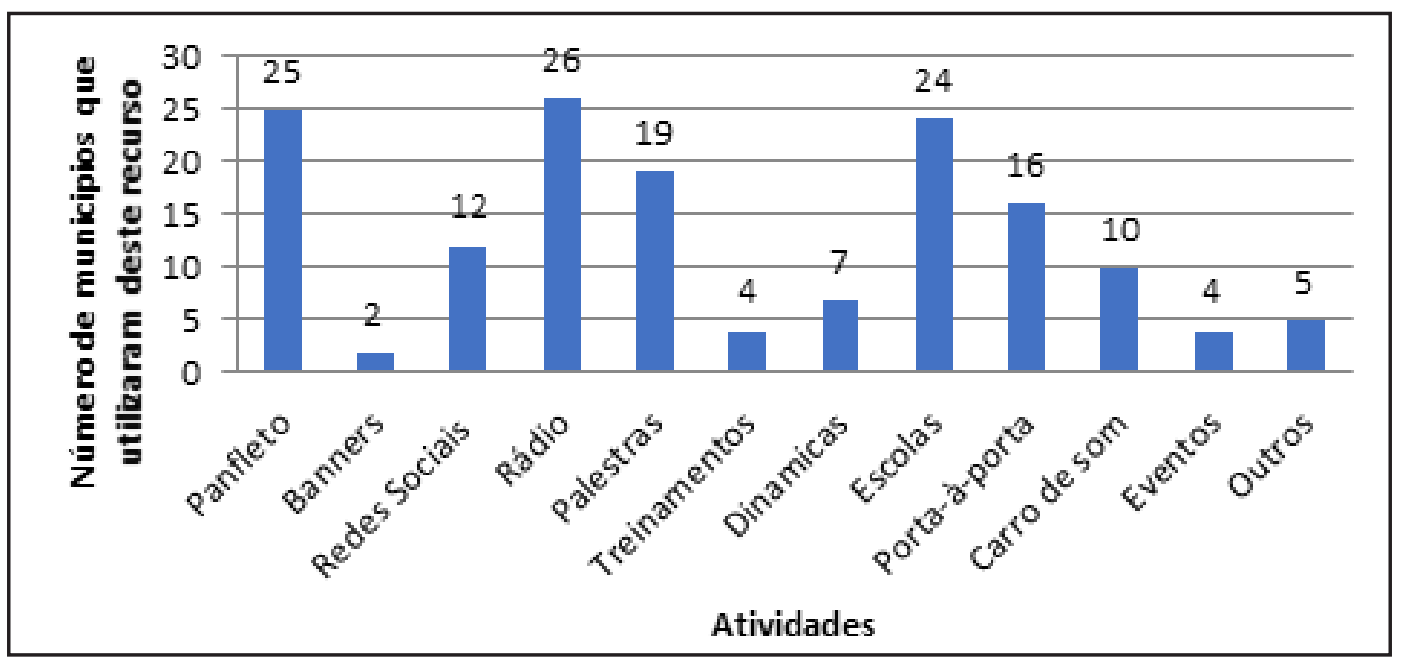

Fonte: Autora (2018) 
da concepção dos gestores.

Dentre os municípios que implantaram a coleta seletiva ou que já fizeram alguma atividade de educação, 17 mostraram-se positivos diante da pergunta, onde afirmam que todas as atividades foram válidas, ou que tiraram algum resultado. Dentre as afirmações destacam-se as falas: "Não tem como mencionar que alguma atividade não foi válida, pois de uma forma ou outra levaram informação a população."; "Todas as atividades foram válidas, sempre se observa algum ganho nas atividades"; "Todas as ações desenvolvidas foram válidas para a conscientização, talvez pecamos por não conseguir desenvolver mais ações".

Aos que arriscaram afirmar que poderia ser melhor citam-se seis municípios, e dentre algumas falas destacamse: "Não identificamos ações inválidas, identificamos ações as quais faltaram efetivação, como é o caso da divulgação através de carro de som, que se torna bastante onerosa, por isso foi paralisada esta ação"; "Audiências públicas, devido a baixa participação da comunidade"; "Palestras, porque é preciso fazer as pessoas entender que o grande problema da coleta seletiva... é o descarte desordenado, inclusive, é o principal gerador de lixões, mesmo assim não cativa os mesmos"; "Panfletagem, muitas pessoas não leem, outras não ouvem rádio".

Das atividades que deram certo, 13 gestores afirmaram ser atividades envolvendo alunos, crianças e a escola em geral. A educação ambiental no contexto escolar é amparada pela Lei no 9.795, de 27 abril de 1999, diz que a educação ambiental estará presente em todas as modalidades do ensino, tais como o ensino básico, infantil, fundamental, superior, especial profissional e chegando até a educação de jovens e adultos (BRASIL,1999). Esta lei só vem reforçar o que afirma a Constituição Brasileira no artigo 205², que fala que a educação é um direito de todos, e confirma a promoção da educação em todos os níveis de ensino para a promoção do meio ambiente (BRASIL,1998). Segundo Virgens (2008), a escola atualmente está voltada para fazer a diferença, gerando discussões e aprendizado. Desta forma, ela tende a preparar os indivíduos para atuar em sociedade, ou seja, formar cidadãos. $\mathrm{Na}$ tabela 9 , citam-se algumas falas dos gestores que se destacaram sobre esse tema.

A escola desempenha um papel extremamente importante na formação do sujeito. O educador, ao trabalhar a educação ambiental com seus alunos, estará contribuindo para que o educando se torne um cidadão consciente em relação ao meio ambiente, capaz de compreender o mundo e agir nele de forma crítica. Ensinar educação ambiental é, principalmente, ensinar o respeito à vida e ao que com ela está relacionado. (AZEVEDO, et al. 2014).

Desta maneira, a educação ambiental em sala de aula é uma necessidade social e cultural. Porém, é bom deixar claro que a mesma não irá resolver todos os problemas ambientais ou salvar o planeta, mas irá criar o respeito e a visão de que se deve cuidar e proteger a natureza para manter as futuras gerações. Uma atividade que se destacou também foi a divulgação porta-a-porta, nove munícipios destacaram a relevância desta ação. Alguns municípios relataram a integração da secretaria da saúde nesta atividade, onde as agentes de saúde tiveram um papel importantíssimo nas ações, pois a mesmas tem um contato direto com as famílias e assim podem passar o conhecimento sobre a coleta seletiva com maior efetividade. E, por fim, as mídias sociais também foram citadas por quatro municípios, os quais afirmaram obter grande divulgação através deste meio, visto que na atualidade muitos tem acesso às informações através deste meios de comunicação.

É notável que este trabalho de educação ambiental é extremamente minucioso, árduo, requer insistência e perseverança. Um trabalho que visa a mudança de atitude dos envolvidos e que busca uma sensibilidade e preocupação com o meio ambiente necessita de muita dedicação e amor pela causa. Infelizmente, na busca pela sustentabilidade, encontram-se diversas interferências que podem desanimar estes agentes transmissores da educação ambiental. Quando questionados se eles sentiam-se motivados com o trabalho de educação ambiental, dos 29 municípios que participaram da pesquisa, 22 gestores disseram estar motivados e empolgados com este trabalho, e em suas falas destaca-se:

"Certamente, procuramos estar sempre nos motivando e ao mesmo tempo motivando as pessoas com as quais convivemos para atingir uma melhor qualidade de saúde pública e ambiental para o nosso município... Entretanto, assim como a maioria dos municípios, também temos nossas

Quadro 4 - Fala dos gestores sobre as atividades que trouxeram maiores resultados

FALA DOS GESTORES

"Palestras e peças teatrais nas escolas realizadas pela equipe do cigres, pois percebe-se que as crianças são atores sociais que tem papel importante para mudanças de costumes no âmbito familiar".

“Divulgação porta-a-porta e nas escolas. São pontos chaves onde está realmente a nossa população".

"Divulgação nas escolas, pois as crianças auxiliam em casa para que seja feita a separação correta do lixo".

"Atividades nas escolas, pelo motivo da acessibilidade de levar a informação a um grande número, a população em geral é mais difícil de se reunir".

Fonte: Autora (2018) 
dificuldades que perpassam pela falta de recursos financeiros, e também pela falta de recursos humanos que gera acúmulo de atividades para poucos, que realmente assumem suas responsabilidades dentro de uma administração pública. Porém, a medida do possível, vamos superando essas dificuldades e procurando desenvolver atividades que reforcem a ideia de que a qualidade da saúde pública e do meio ambiente como um todo depende de cada um de nós, não somente de uma administração pública ou de um órgão ambiental. Pois, por mais que os servidores públicos se esforcem e façam sua parte, se não houver a conscientização e a reponsabilidade da população, não haverá êxito no processo da separação dos resíduos"

"Com certeza é um trabalho que vale a pena, desde que você tenha vocação para trabalhar nesta área, pois é um trabalho que deve ser muito persistente porque que não éfácil mudar a mentalidade da população. Também é um trabalho que precisa ser feito em equipes e em várias formas de levar a informação para a sociedade".

"Sim, pois devemos reduzir os impactos que geramos ao meio ambiente, e a coleta seletiva é uma importante ferramenta para minimizar estes impactos. Quando separamos nossos resíduos corretamente, grande parte destes serão reaproveitados gerando renda, minimizando a necessidade de exploração de fontes primária e reduzindo significativamente a quantidade de rejeito, o que acarreta no aumento da vida útil dos aterros sanitários"

"Sim, é um desafio, e buscamos alcançar as metas estabelecidas, não só para a economia do município, mas sim para as melhorias do meio ambiente".

"Sim, porque buscamos a preservação do meio ambiente a fim de proporcionar uma vida saudável para a população. Desta forma auxiliaremos para que todos os seres vivos, sejam eles terrestres, aquáticos ou aéreos consigam ter um crescimento e desenvolvimento mais saudável em seu habitat".

"Sim, pois um trabalho com motivação se torna mais produtivo...".

"Sim, pois com o planejamento da coleta seletiva a efetividade foi satisfatória, porém, gostaríamos de ter mais acessos e reuniões para debater sobre a organização entre o CIGRES e os municípios".

"Sim, é difícil e demorado, porém de grande relevância".

"Sim, sinto-me motivado muitíssimo, pelo resultado que está sendo colhido pela preservação do meio ambiente e o reconhecimento da população pelo trabalho desenvolvido, pois hoje temos uma cidade mais limpa e consciente da preservação ambiental."

"Sim, não só pelo fato de ser um defensor do meio ambiente, mas também pelo motivo de que a educação ambiental é o primeiro passo para que tenhamos sucesso neste trabalho de coleta e reciclagem do nosso lixo...”.

$\mathrm{O}$ restante (quatro gestores) afirmaram estarem desanimados ou desmotivados, encontrando muitas resistências, dificuldades, falta de colaborações e incentivos. Destaca-se as seguintes respostas:

"Não. Porque falta de uma cultura comunitária para os princípios dos 3Rs (Redução, Reutilização e Reciclagem), participação, emancipação e, ainda, a falta de pesquisa direcionada para a preservação do meio ambiente de forma sustentável. Em outras palavras, faltam principalmente políticas públicas e privadas que reduzam a produção de lixo e a poluição da natureza, bem como a exploração dos recursos naturais de forma predatória e criminosa. O lixo e o tratamento dado a ele têm que deixar de ser um problema oculto aos olhos da população Cristalense, e requer providências urgentes por se tratar de qualidade de vida das pessoas e do planeta. É necessário que se tenha consciência também da necessidade de técnicas eficientes na decomposição das matérias orgânicas (como a compostagem), bem como mudar os padrões de produção e consumo de matérias".

"Muitas vezes não, devido a falta de participação da população na separação dos resíduos nas suas residências e também acabam colocando nas lixeiras nos dias incorretos para não armazenar em casa, e a dificuldade em realizar um trabalho complexo muitas vezes sozinha, pois não tem funcionários mobilizados para conscientização da população".

É possível perceber que o educador ambiental deve estar ciente que este trabalho não é uma tarefa fácil. Na última questão foi solicitado que os gestores apresentassem conselhos e orientação aos educadores ambientais que estão por iniciar este trabalho na gestão de resíduos sólidos, dentre as respostas destacam-se as seguintes orientações para que o trabalho seja concreto e efetivo:

“- Dimensionar primeiramente o volume de cada tipo de resíduo gerado (recicláveis, orgânicos e rejeitos) para que, conforme o volume do caminhão, se dimensione a rota que irá fazer; - Levar em consideração conforme a quantidade de dias que será segurado em casa cada tipo de resíduo; as lixeiras e o caminhão devem comportar tal volume de armazenagem acumulado; - Divulgação porta-a-porta com treinamento e auxílio das agentes de saúde e visitadoras do PIM teve grande efeito na sensibilização; - Divulgar um mapa com a área de abrangência da coleta seletiva; Separar os dias de coleta do reciclável e do orgânico, pois geralmente as pessoas misturam estes dois tipos de resíduos. A mudança do recolhimento do turno diurno para noturno foi que teve grande sucesso, devido ao baixo tráfego de veículos, conforto térmico para os servidores, entre outros. - Disposição de lixeiras de aproximadamente 50 metros de distância umas de outras. Evita-se muitas paradas do caminhão e organiza a coleta. - Capacitação dos servidores que fazem a coleta, orientando sobre os tipos de resíduos coletados e cobrando que os resíduos misturados ou fora de dia do recolhimento não sejam recolhidos. - Orientar a população por meio das emissoras de rádios a somente colocar os resíduos respectivos de cada dia da coleta seletiva. - Criar um Conselho Municipal de Saneamento Básico ou similar para debater sobre o assunto; Dicas como: - Possuir obrigatoriamente no mínimo 3 lixeiras dentro de casa; - No momento de colocar as sacolas para a coleta, não colocar um dentro de outra (exceto do mesmo tipo de resíduo); - Troca da denominação de rejeito para sanitário (facilitou o entendimento)".

"Criando legislação própria sobre o tema, conscientizando a população, formando comitês d e frente de trabalho para desenvolver as atividades previstas relativa a preservação do meio ambiente".

"Em longo prazo, é preciso enfrentar os desafios impostos pela cultura das sociedades modernas ao consumismo irresponsável e imponderável, com foco no bem estar social 
sustentável, destacando a importância do marketing social para a construção e desenvolvimento de uma postura voltada para a ecoeficiência. O processo de educação ambiental continuada deve preocupar-se com a formação de educadores ativos, propositores, reflexivos e re-alimentadores dos procedimentos e metodologias, por meio dos princípios já citados acima: participação, emancipação, autonomia”.

"Tentar a mobilização da maior quantidade de funcionário possível da prefeitura para ajudar na divulgação, pois a conscientização e mudanças dos hábitos no município não acontece de forma rápida”

"O trabalho de implantação da coleta seletiva é intenso e necessita de parcerias que estejam comprometidas com o tema, a conscientização ambiental é fundamental para o sucesso do trabalho".

"Primeiramente, que estudem e se apropriem do tema que pretendem abordar junto à população. Disponham de todo o tipo de material para auxiliá-los no trabalho. Utilizem o maior número de meios de comunicação possível, mas não dispensem o contato direto com a população, indo de porta a porta, levando a informação. Segundo, sejam persistentes, porque as dificuldades sempre irão surgir, mas acreditem na sua capacidade de contribuir para um mundo com uma qualidade de vida melhor. Terceiro: Busquem o apoio de todos os órgãos (públicos e privados) entidades diversas que de alguma forma possam assumir a responsabilidade de fazer a implantação da coleta seletiva dar certo”.

"Trabalhar com os gestores da administração a importância de se ter um funcionário específico para a atividade, ao menos até a efetividade da implantação da coleta seletiva”.

"Muita persistência, paciência e dedicação".

Educação ambiental é a palavra chave para o sucesso deste trabalho, arraigar na sociedade, a ideia de que se todos contribuírem o mínimo possível, todos juntos, farão uma mudança gigantesca no final do processo, no entanto é fundamental, impor aos agentes envolvidos as devidas adequações. Sendo assim, instituir metas, ações e também penalizações capazes de despertar os indivíduos a tomarem consciência da situação catastrófica do mau gerenciamento de resíduos, e fará com que os mesmos adquiram conhecimentos, habilidades, experiências, valores e cidadania, fatores esses, determinantes para os tornarem capazes de agir, individual ou coletivamente, na busca de soluções para os problemas ambientais, presentes e futuros.

\section{Conclusões}

Este trabalho possibilitou entender que o processo de implantação da coleta seletiva é um processo difícil, lento e contínuo, em virtude disso, os resultados esperados são significativamente demorados, o que muitas vezes desmotiva quem está à frente a esta implantação. Com isso, pôde-se perceber que apenas 19 municípios dos 31 participantes do Consórcio Intermunicipal de Gestão de Resíduos Sólidos-CIGRES implantaram efetivamente o sistema em sua gestão, o que percebe a necessidade de projetos e ações eficazes a fim de subsidiar o sucesso do mesmo.
Dentre as dificuldades encontradas neste processo que se destacaram foi a falta de colaboração da população, no entanto, nenhum indivíduo é passível de mudança se não houver um fator externo que o motive. Essa tarefa tão delicada no processo de implantação da coleta seletiva municipal é incumbida aos gestores ambientais. Notou-se, com o resultado da pesquisa que os gestores ambientais estão encontrando grandes dificuldades na sensibilização dos munícipes, desta forma, é imprescindível, que o educador ambiental entenda as necessidades e formule planos de ação a fim de trazer esta problemática para a discussão e encontrar recursos que obtenham melhores êxitos dentro de cada realidade. Observaram-se muitos outros pontos que dificultam esse processo de implantação e sensibilização para a coleta seletiva, dentre elas destacamse as falhas estruturais do órgão ambiental, ausência de recursos financeiros, falta de apoio da administração do município dentre outros empecilhos.

Apesar de muitas dificuldades, observaram-se também muitas atividades e ações que obtiveram sucesso e que se destacaram nos municípios, os mesmos foram expostos no encontro o qual foi muito proveitoso e pode-se trocar experiências e entender melhor este processo e a realidade de cada município, contribuindo assim para a construção de conhecimento sobre a temática e incentivando os municípios que estão em fase inicial de implantação ou que ainda não conseguiram implantar a coleta seletiva. Portanto, demonstra-se a necessidade de avançar em termos de coleta seletiva de resíduos para obter resultados econômicos, sociais e ambientais satisfatórios. Das soluções para a questão podem ser assim definidas: atuação do Poder Público de forma mais efetiva na coleta seletiva, na fiscalização, disponibilização de recursos financeiros, no estímulo à população à mudança de hábitos, neste contexto destaca a importância da educação ambiental no processo de implantação dos projetos e ações permanentes e contínuas voltadas à área ambiental e na imposição de sanções cabíveis.

\section{Agradecimentos}

A UFSM, instituição de ensino que proporciona aprendizagem, conhecimento e trocas de experiências, a equipe do CIGRES pela cooperação e a todos os representantes dos munícipios que se dispuseram a participar da pesquisa.

\section{Referências}

BRASIL, Lei $\mathrm{N}^{\circ} 12.305$ de 02 de agosto de 2010 - Política Nacional de Resíduos Sólidos (PNRS), Brasília, 2010.

BRASIL. Constituição (1988). Constituição da República Federativa do Brasil. Brasília, DF: Senado Federal: Centro Gráfico, 1988.

BRASIL, Lei 9795. Política Nacional de Educação Ambiental, Brasília: Diário Oficial da República Federativa do Brasil, Brasília, 1999. 
GUIMARÃES A. Falta Educação ambiental para quem mais precisa. 2008. Disponível em: https://novaescola. org.br/conteudo/2894/falta-educacao-ambiental-paraquem-mais-precisa Acesso em: 01/10/18.

HEBER, F.; SILVA, E. M. D. Institucionalização da Política Nacional de Resíduos Sólidos: dilemas e constrangimentos na Região Metropolitana de Aracaju (SE). Rio de Janeiro: Rev. Adm. Pública, v. 48, n. 4, p. 913-937. 2014.

IPEA- INSTITUTO DE PESQUISA ECONÔMICA APLICADA, Sensibilização E Mobilização Dentro Da Política Nacional De Resíduos Sólidos: Desafios e Oportunidades da Educação Ambiental, Texto para discussão/ Brasília: IPEA, Rio de Janeiro, 2012.

IPEA- INSTITUTO DE PESQUISA ECONÔMICA APLICADA. Situação Social das Catadoras e dos Catadores de Material Reciclável e Reutilizável, Brasília: IPEA, Rio de Janeiro, 2013.

MINISTÉRIO DO MEIO AMBIENTE. Plano Nacional de Resíduos Sólidos. 2012. Disponível em: http:// www.mma.gov.br/estruturas/253/_publicacao/253_ publicacao02022012041757.pdf Acesso em: 20 de set de 2018.

MAIEllo A.; BRITTO A. L. N. DE P. \& VALLE, T. F. Implementação da Política Nacional de Resíduos Sólidos. Rio de Janeiro: Rev. Adm. Pública, vol.52 nำ 1.2018

NOGUEIRA, C. F. DE A. Política Nacional de Resíduos Sólidos, Coleta Seletiva e seus Atores - o caso do Distrito Federal. Distrito Federal: Revista Brasileira de Direito, vol. 10 no 1.2014.

OLIVEIRA, T. B. \&, JUNIOR, A. C. G. Planejamento municipal na gestão dos resíduos sólidos urbanos e na organização da coleta seletiva Rio de Janeiro: Scielo. Eng. Sanit. Ambient., vol.21 no.1, 2016.

OLIVEIRA, D. A. M. Percepção de riscos ocupacionais em catadores de materiais recicláveis: estudo em uma cooperativa em Salvador-Bahia. Dissertação (Mestrado em Saúde, Ambiente e Trabalho) - Universidade Federal da Bahia, 174 f Salvador, 2011.

SCHALCH, V. W. LEITE, C. A.; JÚNIOR , J. L. F.; DE CASTRO, M.C. A. A. Gestão E Gerenciamento De Resíduos Sólidos- Universidade de São Paulo Escola de Engenharia de São Carlos, Departamento de Hidráulica e Saneamento. São Carlos, 2002.

STUMPF, U.; D. THEIS, V. \& SCHREIBER, D. Gestão de Resíduos Sólidos em Empresas Metalomecânicas De Pequeno Porte. São Paulo: Rev. Gest. Ambient. Sustentabilidade, Vol. 7, N. 2, 2018.

VIANA, D. S. M.; BARROS, E. S. M.; SOARES, Z. T. Lixo: o que fazer? Rev. Educação Ambiental em Ação, n.57, ano 16, 2016.
VIRGENS, R. A. Educação Ambiental no Ambiente Escolar, 2011. 26 F. Trabalho de Conclusão de Curso (Licenciatura em Biologia)- Universidade de Brasília, Brasília, 2011.

WESLEY R. S. F. E CHARBEL J. C. J. Utilizando Estudo de Caso(S) Como Estratégia De Pesquisa Qualitativa: Boas Práticas E Sugestões. Lajeado: Rev. Estudo \& Debate, v. 18, n. 2, 2011. 